\title{
A Durable, High-Performance Hollow-Nanofiber Cathode for Intermediate- Temperature Fuel Cells
}

\author{
Yu Chen ${ }^{\mathrm{a}}$, Yunfei Bu ${ }^{\mathrm{a}}$, Bote Zhao ${ }^{\mathrm{a}}$, Yanxiang Zhang ${ }^{\mathrm{b}}$, Dong Ding ${ }^{\mathrm{a}}$, Renzong $\mathrm{Hu}^{\mathrm{a}, \mathrm{c}}$, Tao Wei ${ }^{\mathrm{a}}$,

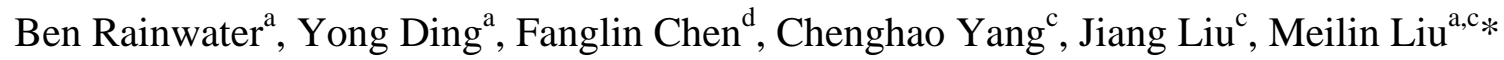

${ }^{a}$ School of Materials Science and Engineering, Georgia Institute of Technology Atlanta, GA 30332-0245, USA.

${ }^{b}$ National Key Laboratory for Precision Hot Processing of Metals, School of Materials Science and Engineering, Harbin Institute of Technology, Harbin, Heilongjiang 150001, China.

${ }^{c}$ New Energy Research Institute, School of Environment and Energy, South China University of Technology, Guangzhou Higher Education Mega Center, Guangzhou, Guangdong, 510006, China.

${ }^{\mathrm{d}}$ Department of Mechanical Engineering, University of South Carolina, 300 Main Street, Columbia, SC 29208, USA.

*Corresponding author: Meilin Liu (meilin.liu@mse.gatech.edu)

\begin{abstract}
Hollow nanofibers of $\mathrm{PrBa}_{0.5} \mathrm{Sr}_{0.5} \mathrm{Co}_{2} \mathrm{O}_{5+\delta}$ (PBSC), created by an electrospinning process, are assembled into a three dimensional (3D) fibrous porous electrode, providing facile pathways for gas transport and excellent electrical conductivity for efficient charge transfer and, thus, greatly enhancing the rate of oxygen reduction reactions (ORR), as confirmed by the small electrode polarization resistance and low activation energy. A simple geometric modelling suggests that an electrode with longer fibers tends to be more efficient in facilitating mass and charge transfer under the conditions studied. A solid oxide fuel cell based on this 3D fibrous cathode demonstrates a peak power density of $1.11 \mathrm{~W} \mathrm{~cm}^{-2}$ at $550{ }^{\circ} \mathrm{C}$ when humidified $\mathrm{H}_{2}$ was used as
\end{abstract}


fuel and ambient air as oxidant. The fibrous architecture also shows excellent stability under the operating conditions. Further and in particular, the high-performance hollow-fiber electrodes are also applicable to other energy storage and conversion systems.

Keywords: SOFC, cathode, ORR, electrospinning, fuel cell, fiber

\section{Introduction}

The two leading fuel cell technologies are polymer exchange membrane fuel cells (PEMFCs, operated at $<200^{\circ} \mathrm{C}$ ) and solid oxide fuel cells (SOFCs, operated at $>600^{\circ} \mathrm{C}$ ), each having their own limitations such as expensive catalyst and limited fuel flexibility for PEMFCs, and sealing issues and system degradation for SOFCs [1, 2]. Intermediate-temperature fuel cells (ITFCs), to be operated at 300 to $550{ }^{\circ} \mathrm{C}$, have potential to overcome the difficulties associated with both low- and high-temperature fuel cells and are ideally suited for a wide range of applications, including distributed generations and electric vehicles. Accordingly, considerable efforts have been devoted to lowering SOFC operation temperature to $<600^{\circ} \mathrm{C}$ through new materials development and optimization of electrode/electrolyte microstructures [3-7]. However, lower operation temperature often leads to higher electrode polarization resistance, due mainly to sluggish oxygen reduction reaction (ORR) [8]. One of the most efficient ways to enhance the cathode ORR activity is to increase the active reaction sites or effective surface area [9]. Nanostructured materials have been extensively studied because of the increased specific surface area and increased surface vacancy concentration [9-12]. Therefore, incorporation of nano-structured catalysts into electrodes represents an effective approach to enhancing electrode performance[10,

13, 14]. While nanoparticles with large surface-to-volume ratio and high electrocatalytic activity may be deposited on electrode surfaces to dramatically enhance fuel cell performance, the 
greatest challenge for these nano-particles decorated electrodes is the long-term stability of the microstructure and activity of the nanoparticles under practical operating conditions.

Recently, one dimensional (1D) nanofiber electrodes with enhanced thermal stability and high electrical conductivity have been explored for SOFCs, aiming to decreasing operating temperature and enhancing stability [15-18]. For example, three dimensional (3D) nano-fiber electrodes for SOFCs $[15,16]$ were reported to have the advantages of high porosity for gas transport, continuous pathway for current collection, and good thermal stability at operating temperatures. In particular, peak power density as high as $\sim 1.33 \mathrm{~W} \mathrm{~cm}^{-2}$ was demonstrated at $800^{\circ} \mathrm{C}$ for a cell with a $\mathrm{La}_{0.6} \mathrm{Sr}_{0.4} \mathrm{Co}_{0.2} \mathrm{Fe}_{0.8} \mathrm{O}_{3}$ (LSCF) fiber cathode and nano-sized $\mathrm{Gd}_{0.1} \mathrm{Ce}_{0.9} \mathrm{O}_{2}$ (GDC) particles. However, the main concern is that the fiber may not survive at the high operating temperature $\left(750-800{ }^{\circ} \mathrm{C}\right)$ for a long period of time. Recently, core/shell fiber structured $\mathrm{Ba}_{0.5} \mathrm{Sr}_{0.5} \mathrm{Co}_{0.8} \mathrm{Fe}_{0.2} \mathrm{O}_{3-\mathrm{d}-}-\mathrm{Gd}_{0.1} \mathrm{Ce}_{0.9} \mathrm{O}_{1.95} \quad$ (BSCF-GDC) cathodes derived from electrospinning and a Pechini process were reported to demonstrate [17]a peak power density of $\sim 2 \mathrm{~W} \mathrm{~cm}^{-2}$ at $550{ }^{\circ} \mathrm{C}$ with hydrogen as the fuel and air as the oxidant, and were operated for 300 $\mathrm{h}$ at a current density of $1 \mathrm{~A} \mathrm{~cm}^{-2}$. The results suggest that stable and high-performance single cells are achievable by modifying the microstructures of SOFC components (anode, electrolyte, and cathode). However, all fiber-based fuel cell electrodes reported so far (including the abovementioned two studies) were coated on electrolyte membrane by painting or brushing a paste of broken fibers due to poor mechanical strength of the fibers $[15,17,19]$. Mechanical mixing/grinding of the fibers with viscous organic media was unavoidable, during which the length, diameter, and microstructure of the fibers would be significantly altered. Electrodes derived from this process consist of "nano-powders" rather than real fibers, not being able to make good use of the unique attributes of the spun fibers of active electrode materials. 
In this work, we report the fabrication of hollow nanofibers as cathodes for high-performance and durable ITFCs. A hollow nanofiber web was directly laminated on a dense electrolyte membrane with the assistance of polyvinyl butyral (PVB) and a slurry of nanoparticles of $\mathrm{Sm}_{0.2} \mathrm{Ce}_{0.8} \mathrm{O}_{2}$ (SDC). Hollow fibers are expected to provide more surface area for ORR [20, 21]. PVB is a resin usually used for applications that require strong binding, optical clarity, adhesion to many surfaces, toughness and flexibility. PVB was first introduced into fiber web by dropping PVB/ethanol mixture and subsequent drying. Leftover PVB matrix can hold the fiber web and provide sufficient mechanical strength and flexibility for the subsequent handling (e.g., punching). The SDC slurry can function as a "glue" to directly connect the fiber web to electrolyte surface during firing. The single cells with intact hollow fiber cathodes showed high performance (peak power density of $\left.1.11 \mathrm{Wcm}^{-2}\right)$ and excellent stability $\left(0.95 \mathrm{Wcm}^{-2}\right.$ at $0.6 \mathrm{~V}$ for $\sim 260 \mathrm{~h}$ ) at $550{ }^{\circ} \mathrm{C}$ when using humidified $\mathrm{H}_{2}$ (3 vol\% water vapor) as fuel and ambient air as oxidant.

\section{Material and Methods}

\subsection{Preparation of $\mathrm{PrBa}_{0.5} \mathrm{Sr}_{0.5} \mathrm{Co}_{2} \mathrm{O}_{5+\delta}(\mathrm{PBSC})$ nanofibers}

The PBSC nanofibers were prepared via electrospinning and subsequent calcination. In a typical procedure for electrospinning, stoichiometric amount of $\operatorname{Pr}\left(\mathrm{NO}_{3}\right)_{3} \cdot \mathrm{xH}_{2} \mathrm{O}$ (x was determined to be 5.8 by thermal gravimetric analysis, TGA), $\mathrm{Ba}\left(\mathrm{NO}_{3}\right)_{2}, \mathrm{Sr}\left(\mathrm{NO}_{3}\right)_{2}$, and $\mathrm{Co}\left(\mathrm{NO}_{3}\right)_{2} \cdot 6 \mathrm{H}_{2} \mathrm{O}$ was dissolved in N,N-dimethylformamide (DMF). Then polyacrylonitrile (PAN) was added to the solution. The mixture was stirred overnight on a hot plate to obtain the precursor solution. The as-prepared PBSC precursor solution was transferred into a syringe equipped with a 25 -gauge needle. The collector was a rotating metal drum wrapped with aluminum foil. The distance 
between the needle tip and the collector was around $15 \mathrm{~cm}$. After a voltage of $15 \mathrm{kV}$ was applied, the fibers formed via the electrostatic forces and deposited on aluminum foil on the rotating metal drum. After electrospining, the electrospun film was dried and then calcined at $950{ }^{\circ} \mathrm{C}$ for $2 \mathrm{~h}$. The phase purity was examined by X-ray diffraction analysis (XRD, X'Pert Pro Alpha-1, using $\mathrm{Cu}$ K- $\alpha 1 \mathrm{X}$-rays). PVB/ethanol (10 wt\%) solution was then dropped into the as-fired fiber mat with a loading of $30 \mu \mathrm{L} \mathrm{cm}^{-2}$. After dried at room temperature $\left(25^{\circ} \mathrm{C}\right)$ for $2 \mathrm{~h}$, ethanol was gone, and the fiber/PVB mat became flexible and was then punched into coupons with diameter of $\sim 0.64 \mathrm{~cm}$.

\subsection{Symmetrical cells and single cells fabrication}

SDC pellets were prepared by uniaxially pressing commercially available SDC powders (Fuel Cell Materials, USA) followed by sintering at $1450{ }^{\circ} \mathrm{C}$ for $5 \mathrm{~h}$ to achieve relative density of 98\%. PBSC hollow nanofiber mats (with PVB) were deposited on SDC pellets using a slurry of $\mathrm{Sm}_{0.2} \mathrm{Ce}_{0.8} \mathrm{O}_{2-\delta}(\mathrm{SDC}, 2-4 \mu \mathrm{m})$ as a bonding layer. The SDC powder was synthesized using a chemical co-precipitation process [22]. The SDC powder was then dispersed in acetone with V006 as binder and ball-milled for $24 \mathrm{~h}$ to form a stable SDC slurry. For comparison, slurries of PBSC, derived from mechanically grinding nanofiber and PBSC powder by solution combustion, were also made and brushed on both sides of SDC pellets, respectively. The SDC pellets with PBSC fiber mats, PBSC nano powder and PBSC combustion powder on both sides, were fired at $950{ }^{\circ} \mathrm{C}$ in air for $2 \mathrm{~h}$, at a heating rate of $1{ }^{\circ} \mathrm{C} / \mathrm{min}$ before $600{ }^{\circ} \mathrm{C}$ and $2{ }^{\circ} \mathrm{C} / \mathrm{min}$ after $600{ }^{\circ} \mathrm{C}$.

NiO-GDC anode substrates ( $12 \mathrm{~mm}$ in diameter) were prepared by freeze-drying tape-casting process. The details can be found in our previous reports [23, 24]. An active NiO-GDC layer $(\sim 15 \mu \mathrm{m})$ and GDC electrolyte $(\sim 15 \mu \mathrm{m})$ were sequentially deposited on the anode support by a particle suspension coating process followed by co-firing at $1450{ }^{\circ} \mathrm{C}$ for $5 \mathrm{~h}$. The cathode fiber 
coupons were then bonded on GDC electrolyte using similar method mentioned earlier for symmetrical cells fabrication. The cathode was subsequently co-fired with SDC on GDC at $950{ }^{\circ} \mathrm{C}$ for $2 \mathrm{~h}$ to form fibrous PBSC electrodes with an active area of $0.32 \mathrm{~cm}^{2}$. For comparison, fiber paste was also prepared by mixing and grinding fiber powder with binder V-006 (Heraeus) at a mass ratio of 1:1. Electrolyte was painted with SDC slurry and fiber powder sequentially, and co-sintered at $950{ }^{\circ} \mathrm{C}$ for $2 \mathrm{~h}$. Before mounting the cells on aluminum tube, $5 \mu \mathrm{L}$ of $0.1 \mathrm{M}$ SDC solution was then dropped into the cathode backbones to enhance electrode performance as well as the bonding between electrode and electrolyte.

\subsection{Characterizations}

The cross-sectional view of the single cells and morphology of hollow fibers was characterized using either scanning electron microscopy (SEM, LEO 1530) or transmission electron microscope (TEM) equipped with energy dispersive spectrum analysis (JEOL 4000 EX). $3 \%$ humidified hydrogen was used as fuel while ambient air was used as oxidant. The current density-voltage curves as well as electrochemical impedance spectra (EIS) of the single cells were measured with a four probe method using a multichannel Versa STAT (Princeton Applied Research) at the operating temperature from $450{ }^{\circ} \mathrm{C}$ to $550{ }^{\circ} \mathrm{C}$. The electrochemical impedance spectra of cells were measured under open circuit voltage over a frequency range of $1 \mathrm{MHz}$ to $0.02 \mathrm{~Hz}$. The long-term stability measurement was implemented with an Arbin multi-channel electrochemical testing system (MSTAT) under a constant voltage of $0.6 \mathrm{~V}$ at $550{ }^{\circ} \mathrm{C}$.

\section{Results and Discussion}

Schematically illustrated in Figure $\mathbf{1}$ is a process for fabrication of an anode-supported cell with a hollow nanofiber cathode. The green fiber tape was prepared by electrospinning the precursor solution of $\operatorname{PrBa}_{0.5} \mathrm{Sr}_{0.5} \mathrm{Co}_{2} \mathrm{O}_{5+\delta}$ (PBSC). The tape was then calcined in air at $950{ }^{\circ} \mathrm{C}$ for $2 \mathrm{~h}$ with a 
ramping rate of $2{ }^{\circ} \mathrm{C} \mathrm{min}^{-1}$. After firing, the hollow PBSC fibers (Figure S1) were composed of nano-sized grains of PBSC (with diameter of $\sim 20-100 \mathrm{~nm}$ ), as seen in the TEM images. The hollow fiber mats have large specific surface area, high porosity, and straight path for efficient mass and charge transfer. To increase the flexibility and mechanical strength of the fibers for further cathode punching/handling, the mat was first flooded with Polyvinyl Butyral (PVB)/ethanol solution, which is a common binder/solvent for commercial tape-casting. After ethanol was removed by drying at room temperature $\left(25^{\circ} \mathrm{C}\right)$ for $2 \mathrm{~h}$, only PVB was left in the fiber mat, providing sufficient mechanical strength and flexibility for subsequent handling (e.g., punching into coupons with a diameter of $\sim 0.64 \mathrm{~cm}$ ). The fiber coupon was then bonded on the top of a GDC electrolyte membrane (supported by freeze-drying tape-casted anode[23]) using a SDC slurry and co-fired at $950{ }^{\circ} \mathrm{C}$ for $2 \mathrm{~h}$ to form a single cell with hollow nanofiber cathode, as schematically shown in Figure 1d.

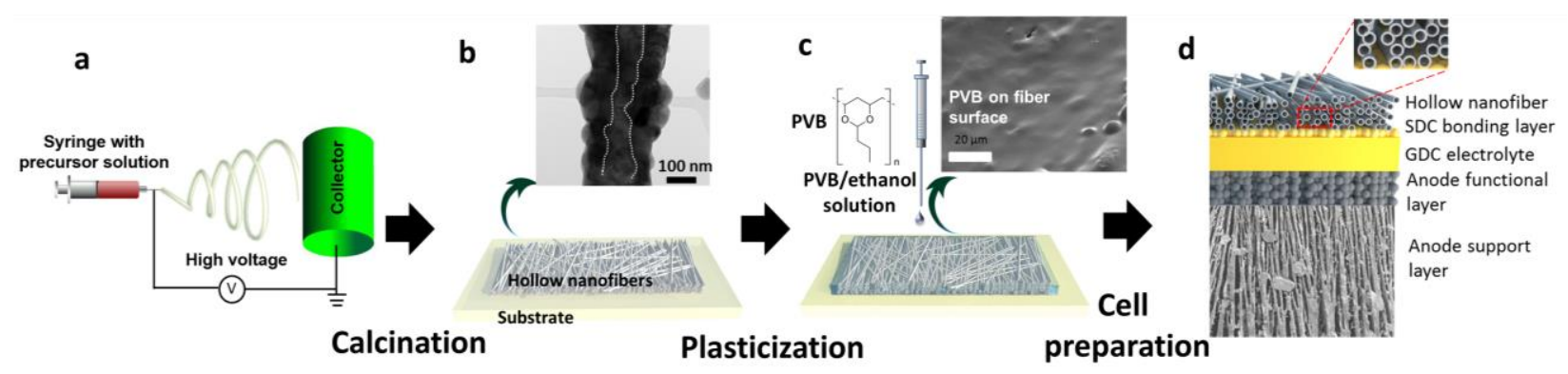

Figure 1 The process for fabrication of an anode-supported cell with a hollow nano fiber cathode: (a) Schematic of apparatus for electrospinning; (b) A typical TEM image of a hollow fiber of PBSC (the bright area in the middle of fiber indicated a hollow-like structure); (c) Plasticization of fiber web by filling calcined fiber mat with binder (PVB); (d) A schematic cross-sectional view of a single cell consisting of an anode functional layer, an anode support layer, a GDC electrolyte membrane, an SDC bonding layer, and a hollow nanofiber cathode.

The PBSC nanofiber electrodes were deposited on SDC electrolyte pellets to make symmetric cells using similar process mentioned earlier. For comparison, a paste of PBSC nano powder 
composed of crushed PBSC fibers and a binder (V006) was also prepared and painted on both sides of SDC pellets. Figure 2 shows the typical impedance spectra of PBSC nanofiber and nano powder electrodes measured at $550{ }^{\circ} \mathrm{C}$, together with the area specific resistance (ASR, $R_{p}$ ) and apparent activation energy $\left(E_{a}\right)$ of each electrode determined from the impedance data shown in Figure S2, S3 and S4. PBSC cathode with hollow fiber structure shows much lower ASR than that with nano powder. For example, the $R_{p}$ at $550{ }^{\circ} \mathrm{C}$ for the hollow fiber cathode is $0.318 \Omega$ $\mathrm{cm}^{2}$, much lower than $0.588 \Omega \mathrm{cm}^{2}$ for the nano powder electrode and $1.26 \Omega \mathrm{cm}^{2}$ for the PBSC electrode derived from the powders prepared by combustion synthesis (Figure S2).

The significant decrease in ASR of the hollow fiber cathode is attributed mainly to the highly hierarchical, porous, and less tortuous pathway for fast mass and charge transport, as illustrated by a simple geometric modeling and simulations of packed fibers of different length and orientation in a cubic matrix. In this simulation, we packed hollow fibers of various lengths in two different ways: close-packed (Figure S5, S6) or packed in a matrix of the same density (kept at 0.3, similar to those of the actual samples) (Figure 3A). In both cases, the outer-diameter and inner-diameter of hollow fibers were kept at $300 \mathrm{~nm}$ and $100 \mathrm{~nm}$, respectively. The angles between hollow fibers and the $x-y$ plane (horizontal plane) were kept in the range of $0-45^{\circ}$. We calculated the porosity, tortuosity factor (for both pores and fibers), and pore radius distribution as a function of the fiber length to evaluate the effect on mass and charge transport in the matrixes, as described in the supplementary materials. For example, for the close-packed sample, longer fibers provide more efficient mass transport (higher porosity, larger pores, and lower tortuosity factor through pores), but worse charge transfer (higher tortuosity factor through fibers) (Figure S5, S6). For the case of a constant fiber packing density of 0.3, as shown in Figure 3B and 3C, the tortuosity factors for both pores and fibers decreased with increasing length of the 
fibers, indicating more efficient pathways for both mass and charge transfer for an intact fiber electrode than the ones derived from crushed fibers or typical powders . This is consistent with our experimental ASR results. Second, the Brunauer-Emmett-Teller (BET) surface area of the hollow nanofibers was $13.44 \mathrm{~m}^{2} \mathrm{~g}^{-1}$, higher than $4.12 \mathrm{~m}^{2} \mathrm{~g}^{-1}$ for PBSC nanopowder and $3.26 \mathrm{~m}^{2} \mathrm{~g}^{-1}$ for PBSC powder derived from a combustion synthesis. The high surface area provides more active sites for ORR. Third, the characteristic frequencies (or the summit frequency determined from the impedance data) of the hollow fiber electrode at each temperature is higher than those of the powder electrodes (Table 1), indicating that the hollow fiber electrodes with lower $R_{p}$ have faster oxygen surface exchange kinetics[25, 26]. This is because the characteristic frequency of the process is inversely proportional to the relaxation time of the electrode process. Thus, the higher the characteristic frequency, the shorter the relaxation time of the electrode process, and the faster the electrode kinetics. For the fiber-based electrodes of hierarchically porous structure, the mass transfer is sufficiently fast so that the overall electrode kinetics is likely limited by oxygen surface exchange kinetics. Accordingly, the higher characteristic frequencies are correlated to the lower $R_{p}$ and faster oxygen surface exchange kinetics of the hollow fiber electrodes.

The intact nanofiber electrodes in this study preserved longer and better-connected hollow fibers, thus offering lower percolation threshold or critical fiber density, $N_{c}$ (in $\# \mu \mathrm{m}^{-2}$ ), which may be estimated from the following equation[27, 28]:

$N_{c}=\frac{1}{\pi}\left(\frac{4.236}{l}\right)^{2}$

where $l$ (in $\mu \mathrm{m}$ ) is the length of the conducting nanofibers. Percolation theory revealed that the conductivity of a fiber electrode is proportional to the fiber density as follows, 
$\sigma \propto\left(N-N_{c}\right)^{\alpha}$

where $\sigma$ refers to the conductivity in three dimensions or the sheet conductance in two dimensions, and $N$ is the conducting fiber density. $\alpha$ is equal to 1.33 for a film in two dimensions and 1.94 for a film in three dimensions $[28,29]$. The intact nanofiber network electrode contains longer fibers thus has lower critical density $\left(N_{c}\right)$ and higher conductivity, compared with those nano powder cathode (derived from crushed fibers or conventional powder)[15, 30]. Considering oxygen molecular, oxygen ions, and electrons need to be transported quickly in and out of the active areas or sites during operation, the hierarchically porous structure composed of hollow fibers greatly facilitates mass and charge transfer required for fast oxygen reduction.

Figure 2b shows the $R_{p}$ and apparent activation energy $\left(E_{a}\right)$ of our PBSC cathodes (hollow nanofiber, nano powder, and the powder from combustion synthesis), together with the ones reported by others $[17,31,32]$. The cathode based on the PBSC powder prepared by combustion has $R_{p}$ and $E_{a}$ values comparable to those of materials with similar composition [31, 32], but lower $R_{p}$ than other conventional mixed ionic-electronic conducting cathodes such as $\mathrm{La}_{0.6} \mathrm{Sr}_{0.4} \mathrm{Co}_{0.2} \mathrm{Fe}_{0.8} \mathrm{O}_{3-\delta}\left(R_{p, 550 \mathrm{oC}}=\sim 10 \Omega \mathrm{cm}^{2}, E_{a}=1.63 \mathrm{eV}\right)[33]$ or $\operatorname{Sm}_{0.5} \operatorname{Sr}_{0.5} \mathrm{CoO}_{3}\left(R_{p, 550 \mathrm{oC}}=\sim 4.48\right.$ $\Omega \mathrm{cm}^{2}, E_{a}=1.31 \mathrm{eV}$ )[34] due to easier oxygen ion diffusion, faster surface oxygen exchange, and higher electrical conductivity[35]. More importantly, the cathodes based on the PBSC hollow nanofiber and the PBSC nano powder show even lower $R_{p}$ and $E_{a}$ in the temperature range of $450-800{ }^{\circ} \mathrm{C}$, implies lower energy barrier to oxygen reduction reaction and faster electrode kinetics[36]. 

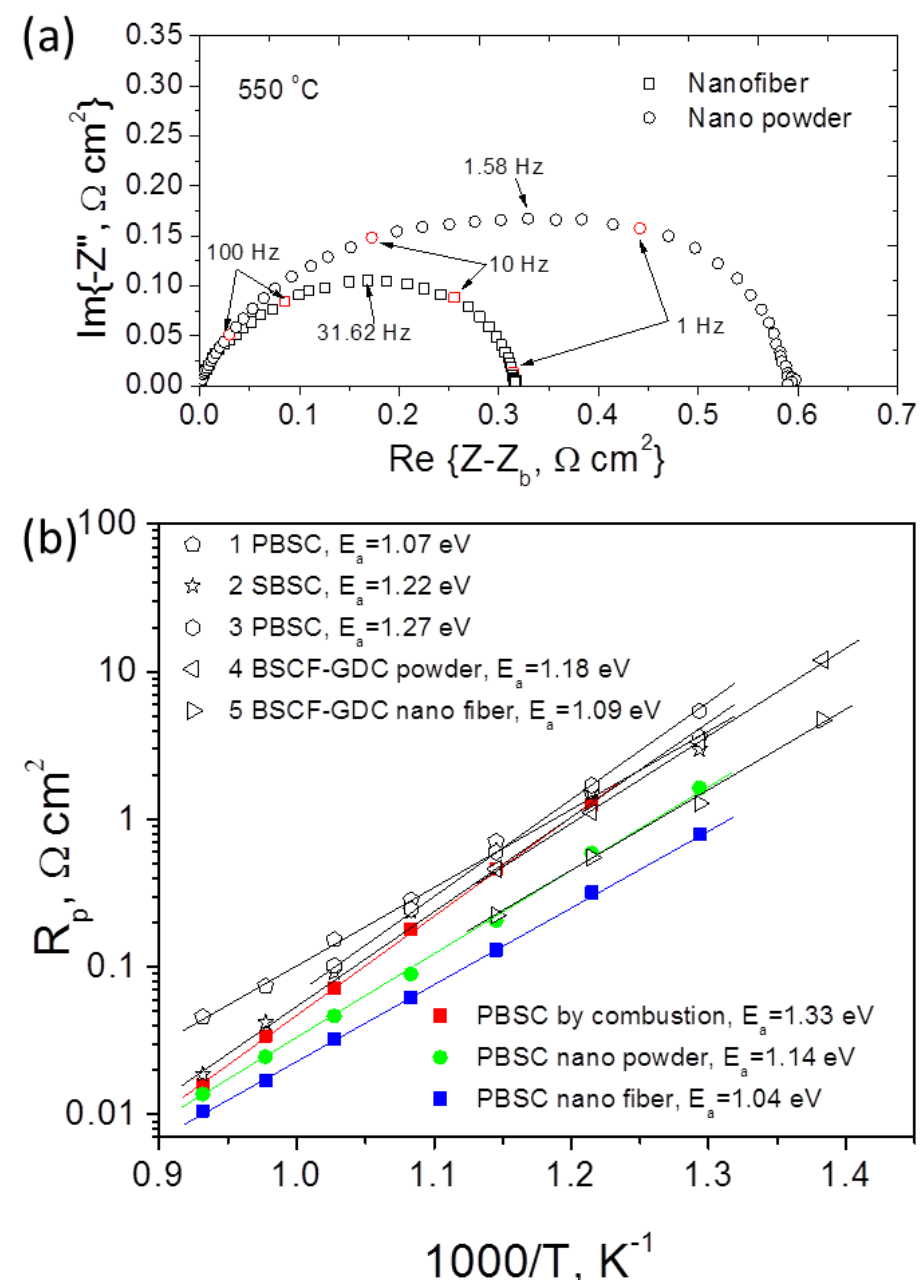

Figure 2 (a) Typical impedance spectra of cathodes based on PBSC hollow nano fiber and nano powder (crushed fiber) measured at $550{ }^{\circ} \mathrm{C}$ under open circuit (OCV) conditions; (b) Comparison of polarization resistance $\left(R_{p}\right)$ and apparent activation energy $\left(E_{a}\right)$ for PBSC hollow nanofiber (blue solid triangle), PBSC nano powder (green solid circle), PBSC prepared by combustion (red solid square), PBSC derivatives or fibers cathode reported by others: 1 PBSC[31], $2 \mathrm{SmBa}_{0.5} \mathrm{Sr}_{0.5} \mathrm{Co}_{2} \mathrm{O}_{5+\delta}(\mathrm{SBSC})_{[31]}, 3 \mathrm{PBSC}[32], 4$ BSCF-GDC powder[17] and 5 BSCF-GDC core-shell fiber[17]. 
Table $1 R_{p}$ and summit frequencies of nanofiber cathode and nanopowder cathode derived from nanofiber at temperature of 500, 550, 600 and $650{ }^{\circ} \mathrm{C}$, determined from EIS curves.

\begin{tabular}{|c|c|c|c|}
\hline Cathode & $\begin{array}{c}\text { Temperature } \\
(\mathbf{C})\end{array}$ & $\begin{array}{c}\text { ASR } \\
\left(\Omega \mathrm{cm}^{2}\right)\end{array}$ & $\begin{array}{c}\text { Summit frequency } \\
(\mathrm{Hz})\end{array}$ \\
\hline Nano fiber & 500 & 0.899 & 7.94 \\
& 550 & 0.318 & 31.62 \\
\hline 600 & 0.109 & 100 \\
\hline & 650 & 0.049 & 316.22 \\
\hline & 500 & 1.630 & 0.50 \\
\hline Nano powder & 550 & 0.588 & 1.58 \\
& 600 & 0.206 & 7.94 \\
\hline 60 & 0.089 & 31.62 \\
\hline
\end{tabular}



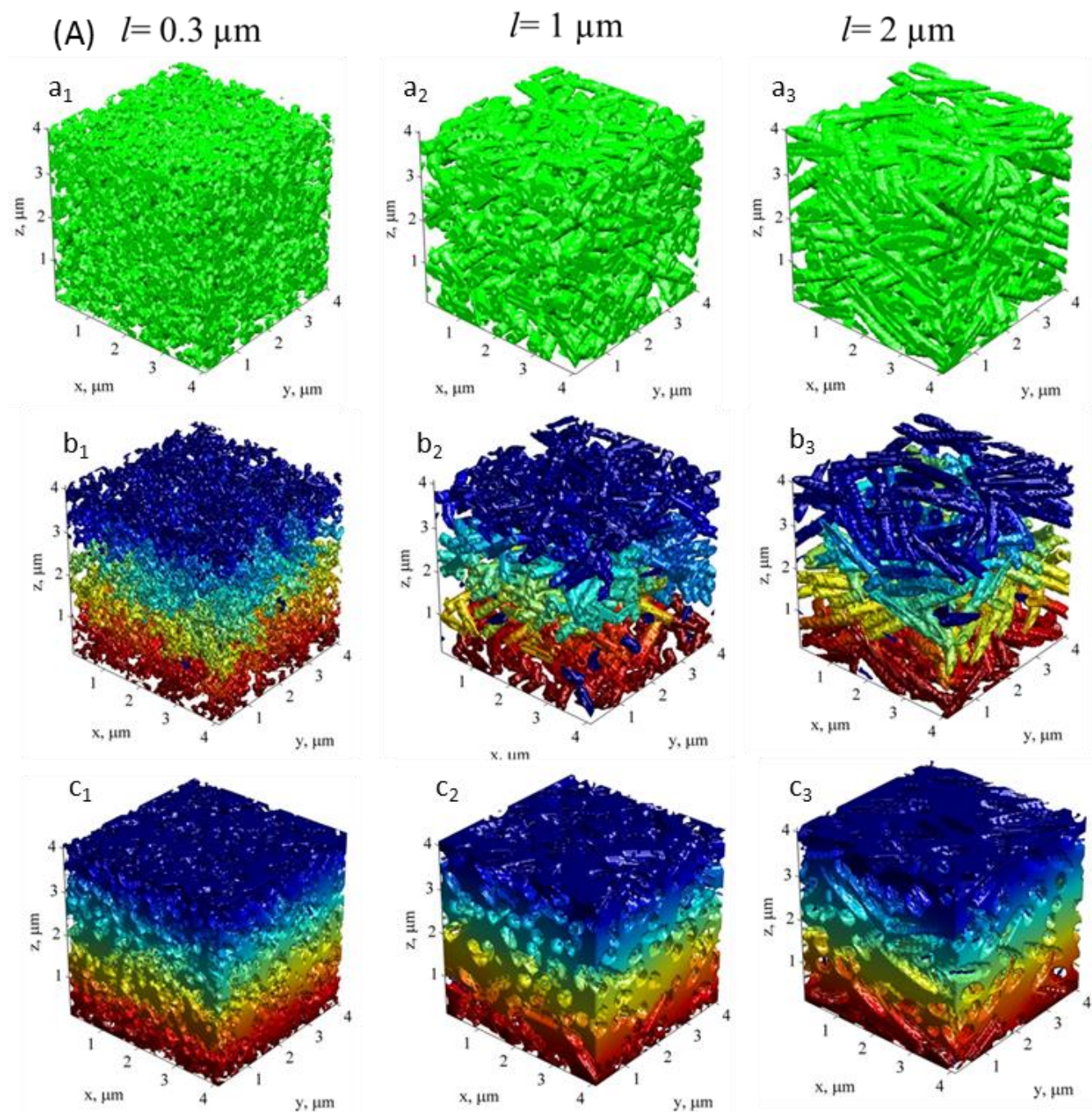

(B)

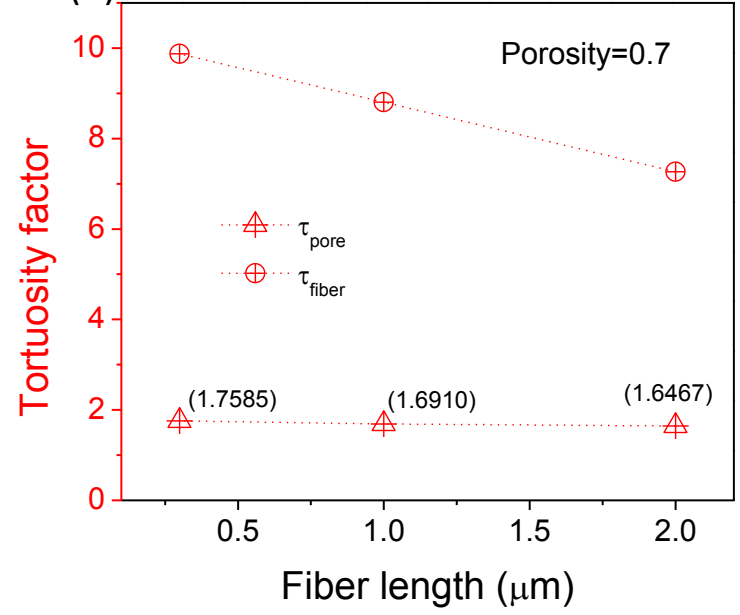

(C)

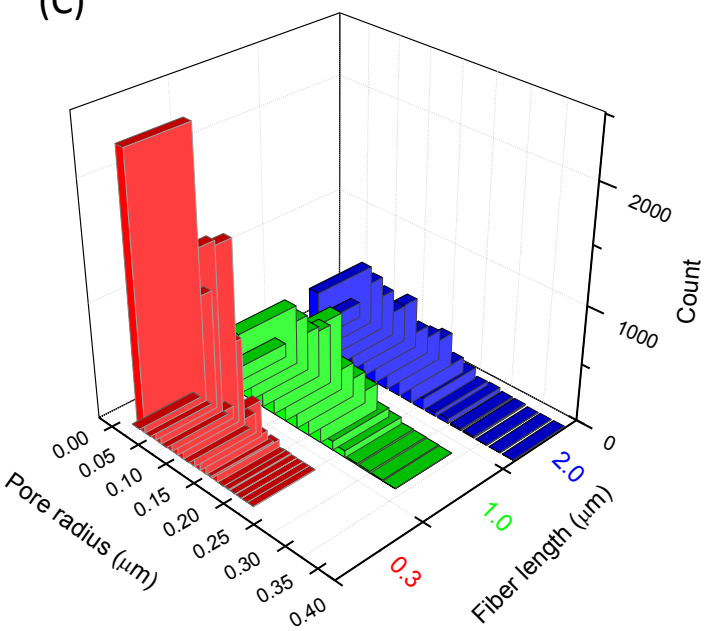


Figure 3 (A) 3D fiber matrix $\left(a_{1}, a_{2}, a_{3}\right)$ with various fiber length $(0.3 \mu \mathrm{m}, 1 \mu \mathrm{m}, 2 \mu \mathrm{m})$ and their generic field within fibers $\left(b_{1}, b_{2}, b_{3}\right)$ and generic field within pores $\left(c_{1}, c_{2}, c_{3}\right)$. The matrices were packed with a constant porosity of 0.7 while keeping the angle of each fiber and $x-y$ plane in the range of $0-45^{\circ}$, and the visualization of a generic field $\psi$ in the 3D matrix by solving Laplace's equation within the fibers and the pores when the field is macroscopically aligned along the $z$-direction. Colors from red to blue represent the field potential from high to low. (B) tortuosity factor of pores and fiber and (C) pore radius distribution of the 3D matrices as a function of fiber length while keeping the porosity at 0.7 and the angle of fiber to $x-y$ plane in the range of $0-45^{\circ}$. It can be concluded that the tortuosity factor for pores and fibers decreased with increaing of fiber length, incidating that longer fibers can provide more efficient mass and charge transfer. 

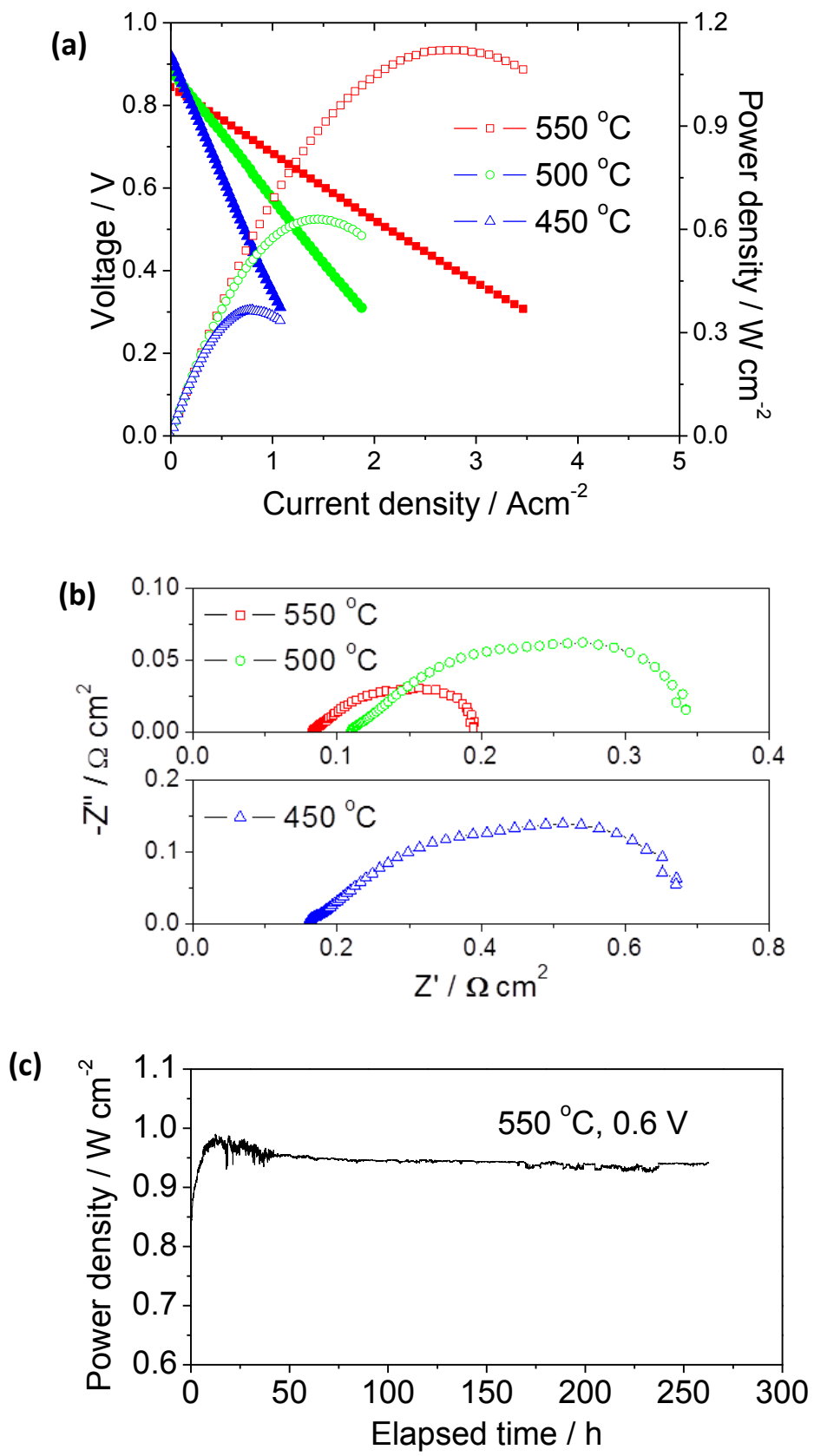

Figure 4 (a) Current-voltage (IV), current-power (IP) curve and (b) impedance spectra for Ni-GDC anode-supported cells with nano hollow fiber cathode measured at 450,500 and $550{ }^{\circ} \mathrm{C}$, respectively. (c) Long-term stability for the single cell operated at $550{ }^{\circ} \mathrm{C}$ at $0.6 \mathrm{~V}$. Humidified $\mathrm{H}_{2}$ (with $3 \mathrm{v} \% \mathrm{H}_{2} \mathrm{O}$ ) was used as fuel and ambient air as oxidant.

Figure 4 shows some typical performances at $450-550{ }^{\circ} \mathrm{C}$ of single cells with the hollow nanofiber cathode. As shown in Figure 4a, the open circuit voltages (OCVs) were 0.92, 0.87 and 
$0.84 \mathrm{~V}$ at 450,500 and $550{ }^{\circ} \mathrm{C}$, respectively, which are typical for cells based on a GDC electrolyte[37] . The peak power densities were about $0.36,0.62$, and $1.11 \mathrm{Wcm}^{-2}$ at 450,500 , and $550{ }^{\circ} \mathrm{C}$, respectively. Figure $\mathbf{4 b}$ shows some typical impedance spectra of the cells under open circuit conditions. The apparent ohmic resistances of the cell, $R_{\Omega}$, corresponding to the high frequency intercept of the impedance spectra with the real axis in the Nyquist plots, are $\sim 0.16$, 0.11 , and $0.09 \Omega \mathrm{cm}^{2}$ at 450,500 and $550{ }^{\circ} \mathrm{C}$, respectively. For a mixed-conducting electrolytes (GDC in this study), the real electrodes polarization resistance, $R_{p}$, can be determined from the following equation[38]:

$$
R_{p}=\frac{R_{t}-R_{\Omega}}{\frac{V_{O c}}{E_{N}}\left[1-\frac{R_{\Omega}}{R_{t}}\left(1-\frac{V_{o c}}{E_{N}}\right)\right]}
$$

where $E_{N}$ is the Nernst potential at the operation temperature, $V_{\mathrm{oc}}$ is the measured $\mathrm{OCV}, R_{\Omega}$ is the apparent ohmic resistance, and $R_{t}$ is the total resistance determined from the low frequency intercept with the real axis in the impedance spectra. The calculated $R_{p}$ values for the cells before stability test were $0.727,0.387$, and $0.169 \Omega \mathrm{cm}^{2}$ at 450,500 , and $550{ }^{\circ} \mathrm{C}$, respectively (Table 2). 
Table 2 Theoretical Nernst potential $\left(E_{N}\right)$, measured OCV $\left(V_{O C}\right)$, apparent polarization resistance $\left(R_{t}-R_{\Omega}\right)$ and corrected polarization resistance $R_{p}$ for the cells under various conditions

\begin{tabular}{|c|c|c|c|c|}
\hline $\begin{array}{c}T \\
\left.{ }^{0} \mathrm{C}\right]\end{array}$ & $\begin{array}{c}E_{N} \\
{[\mathrm{~V}]}\end{array}$ & $\begin{array}{l}V_{o c} \\
{[\mathrm{~V}]}\end{array}$ & $\begin{array}{c}R_{t}-R_{\Omega} \\
{\left[\Omega \mathrm{cm}^{2}\right]}\end{array}$ & $\begin{array}{c}R_{p} \\
{\left[\Omega \mathrm{cm}^{2}\right]}\end{array}$ \\
\hline $450^{a)}$ & 1.160 & 0.92 & 0.551 & 0.727 \\
\hline $500^{a)}$ & 1.152 & 0.87 & 0.242 & 0.387 \\
\hline $550^{a)}$ & 1.144 & 0.84 & 0.111 & 0.169 \\
\hline $550^{b)}$ & 1.144 & 0.84 & 0.170 & 0.251 \\
\hline $550^{c)}$ & 1.144 & 0.84 & 0.094 & 0.147 \\
\hline
\end{tabular}

a)Cells with hollow nanofiber cathode before stability test; b) Cells with nano powder ; c) Cells with hollow nanofiber cathode after stability test

Our results $\left(P_{\max }\right.$ of $1.11 \mathrm{Wcm}^{-2}$ at $550{ }^{\circ} \mathrm{C}, \sim 15 \mu \mathrm{m}$ of GDC in our study) is comparable with the best single cell performance related with nanofiber cathode (composite core-shell BSCF-GDC fiber) is reported by Shul et al[17]. In that report, the cell showed a $P_{\max }$ of $1.14 \mathrm{Wcm}^{-2}$ at $550{ }^{\circ} \mathrm{C}$ when electrolyte is $9 \mu \mathrm{m}$-thick ${ }^{[17]}$. Considering that the cathode was BSCF-GDC composite with unique core-shell structure, potentially with enlarged triple phase boundary, it is anticipated that our cell performance could be further improved by electrode surface modification. In our cell design, the hierarchically oriented pores in the Ni-GDC anode (prepared by a freeze-drying tapecasting process) and the intact hollow nanofiber cathode are expected to reduce the resistance to mass transport and, thus, further enhancing cell performance[23].

Figure 4c shows the long-term stability $(\sim 260$ h) when the cell was operated under a constant voltage of $0.6 \mathrm{~V}$ at $550{ }^{\circ} \mathrm{C}$. In the first $10 \mathrm{~h}$, the power output increased with time, which might 
be attributed to some conditioning process. For example, the cathode microstructure evolution might have resulted in a better-connected nano-network, with higher mixed ionic-electronic conductivity than that of the initial hollow fiber web, as reflected from the impedance data acquired during the process (Figure S7). The calculated polarization resistance decreased from 0.169 to $0.147 \Omega \mathrm{cm}^{2}$ after $210 \mathrm{~h}$ operation (Table 2). As shown in Figure 4c, after operation of about $48 \mathrm{~h}$, the cell power output was stabilized at $\sim 0.95 \mathrm{Wcm}^{-2}$ and the cell was operated for another $221 \mathrm{~h}$ with little degradation $(\sim 2.1 \%$ decrease in $221 \mathrm{~h})$, demonstrating good electrochemical stability of hollow nanofiber cathode.

To validate the advantage of the cathode with intact hollow nanofibers, we have also evaluated the performances of the cells with a cathode based on nano powder or crushed fibers (Figure S8), demonstrating a peak power density of only $0.79 \mathrm{Wcm}^{-2}$ at $550{ }^{\circ} \mathrm{C}$ under similar testing conditions (Figure 5a). The impedance spectra of those cells with nano powder cathode have also been collected and compared with those cells with hollow nanofiber cathodes (Figure 5b). The calculated $R_{p}$ was $\sim 0.251 \Omega \mathrm{cm}^{2}$ for those cells with a nano powder cathode (Table 2 ), which is $\sim 47 \%$ higher than those of the hollow nanofiber cathodes. 

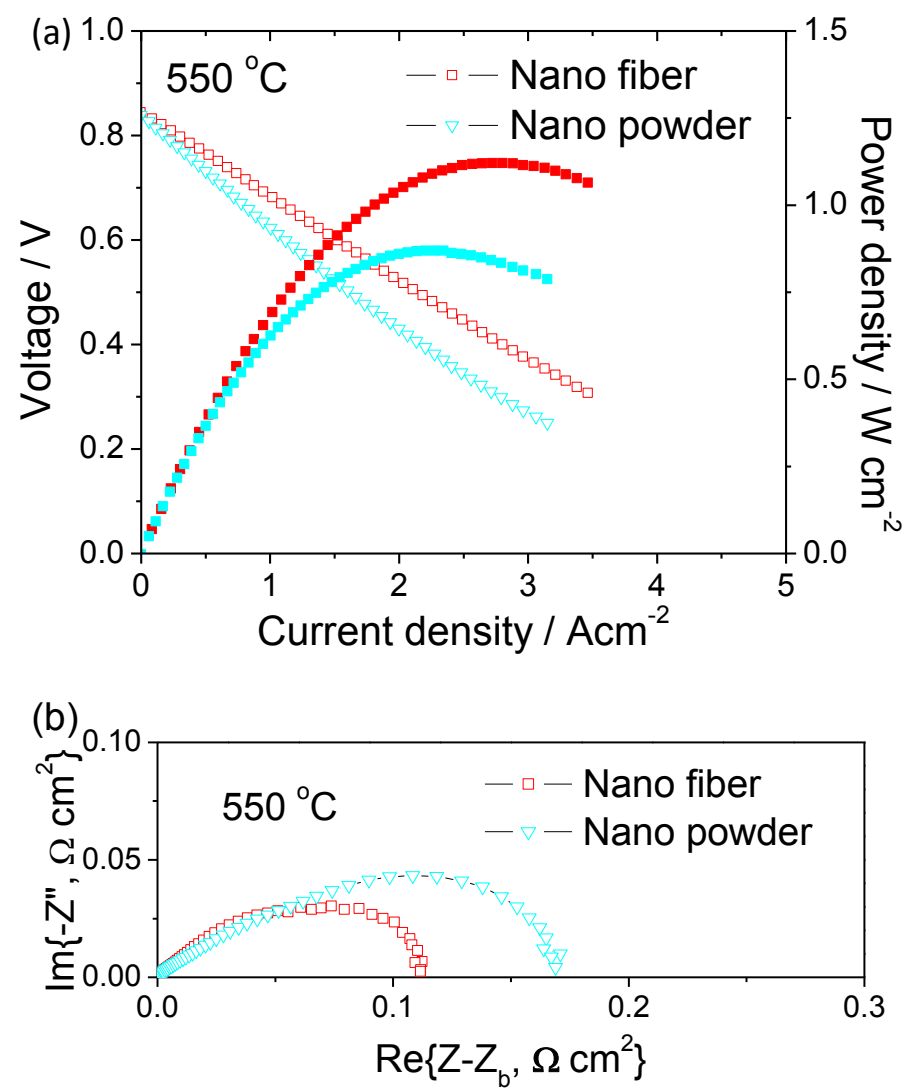

Figure 5 (a) Current-voltage (IV) and current-power (IP) curves and (b) impedance spectra of single cells with hollow nano fiber cathode and nano powder cathode. The composition and microstructure of the anode and the electrolyte for the two cells were kept identical. The only difference is the cathode.

The high performance and excellent stability can be attributed to the novel microscopic features of the hollow nanofiber cathode and the unique anode, as seen from the cross-sectional images shown in Figure 6. The nanofiber cathode was well adhered to the GDC electrolyte with the help of a 2-4 $\mu \mathrm{m}$ thick SDC bonding layer (Figure 6a). The anode support, derived from a freezedrying tape-casting process, has a porosity of $\sim 50 \%$ and tortuosity factor (along gas diffusion direction) of $\sim 1.3[23]$. The straight and open pores/channels (Figure 6b) facilitate fast mass transport and efficient current collection. As shown in Figure 6c, the long hollow fibers were bonded well with the SDC bonding layer, establishing excellent electrical contact between the fiber electrode and the electrolyte. The hollow fibers may be formed by outward diffusion of the 
as-generated gases from oxidization of the polymer additives and decomposition of metal precursor during the firing process. Similar hollow oxide fibers have also been reported via single-nozzle electrospinning technique with a subsequent proper firing process[21, 39-41]. The hollow nanofiber structure is expected to provide larger surface area and higher porosity, facilitating oxygen reduction reaction and gas diffusion. As shown in Figure 6d, the surface of hollow fiber was coated with nano SDC particles, created through infiltration of an SDC precursor solution during fabrication. These nano SDC particles on the hollow fibers are believed to increase the TPB length, enhance the catalytic activity for oxygen reduction reaction, and improve the stability of the cathode[13]. It is also noted that the addition of these SDC nano particles has minimal effect on the rate of mass transport, as suggested by a simple geometric simulations of packed-fibers of various lengths with $10 \mathrm{vol} \%$ SDC infiltrate (very close to our experimental loading of $9.4 \mathrm{vol} \%$ ) (Figure S9, S10). For example, the tortuosity factor $\left(\tau_{\text {fiber }}\right)$ for a packed-fiber ( $2 \mu \mathrm{m}$ long) with $10 \mathrm{vol} \%$ SDC infiltrate was 4.05 , much smaller than that for the same fiber matrix without SDC infiltrate (7.27). Meanwhile, the $\tau_{\text {pore }}$ only changed from 1.64 (without SDC) to 2.34 (with SDC). Thus, the introduction of SDC nanoparticles can facilitate the charge transfer significantly, but has little effect on mass transport.

The detailed features of the hollow nanofiber structure are further revealed by transmission electron microscopy (TEM) and scanning transmission electron microscopy (STEM). The highangle annular dark-field (HAADF) STEM images (Figure 6e and Figure S11a) and bright-field TEM images (Figure S11b) indicate that the hollow channel inside the fiber is relatively uniform and has a diameter of $\sim 150 \mathrm{~nm}$. An elemental profile along the line vertical with fiber (Figure S11a, c) indicates that the nano PBSC particles on surface of fiber were further coated with finer nano-sized SDC particles (Figure S11d). The hierarchical nano structure may facilitate not only 
the oxygen diffusion and ORR but also current collection due to better electrical connection between fibers in cathode. Figure $\mathbf{6 f}$ is an electron energy-loss spectroscopy (EELS) spectrum from the spot shown in (e) on the fiber, in which the peaks corresponding to $\mathrm{O}, \mathrm{Co}, \mathrm{Ce}, \mathrm{Pr}$ and Sm can be clearly identified. Ba and Sr cannot be identified in EELS since the energy loss for them is beyond $1150 \mathrm{eV}$, but can be found in X-ray energy dispersive spectroscopy (EDS), as shown in Figure S12.
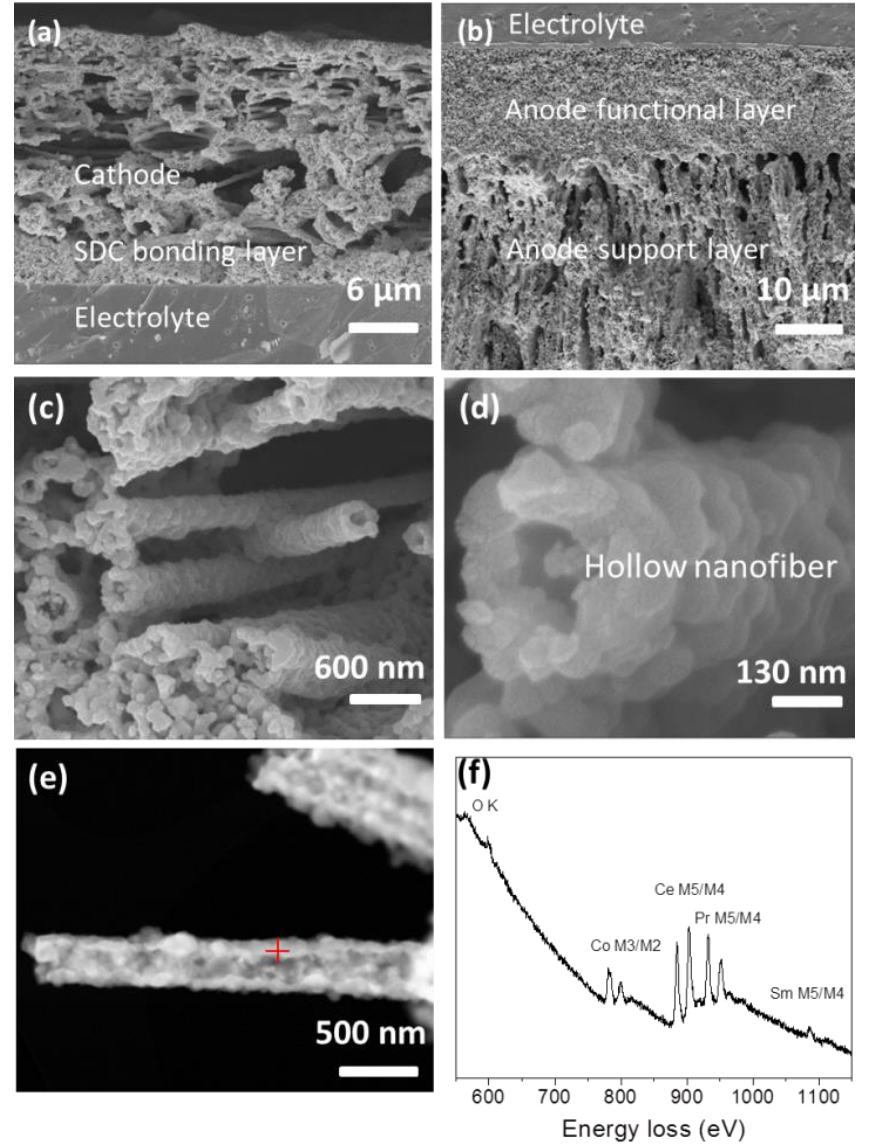

Figure 6 Cross-sectional images of a cell after being tested at $550{ }^{\circ} \mathrm{C}$ for $\sim 260 \mathrm{~h}$ : (a) the cathode (PBSC nanofiber with SDC coating), the SDC bonding layer, and the GDC electrolyte showing good adhesion of the cathode to the electrolyte layer; (b) a Ni-GDC anode-electrolyte interface showing the straight and open pores/channels for fast mass transfer; (c) a closer view of the cathode consisting of intact hollow fibers seen in (a); (d) an individual hollow 
fibers seen in (c); (e) HAADF STEM images of the hollow nanofiber electrode after electrochemical measurement and (f) EELS spectrum from a red spot on the wall of fiber (e).

In general, the performance of a cathode is influenced by three major factors: (1) the rate of mass transfer through the pore of the electrode (the transport of oxygen to and oxygen ions away from the active sites for ORR), the rate of ionic and electronic defect transport through the solid phase, and the rate of oxygen reduction reactions (ORR) at the electrode surfaces or electrode/ $\mathrm{O}_{2}$ interfaces. The oxygen reduction reaction $\left(\frac{1}{2} \mathrm{O}_{2}+2 e^{-} \rightarrow \mathrm{O}^{2-}\right)$ involves a number of surface processes, including adsorption of oxygen molecules on adsorption sites, dissociation of oxygen molecules to monoatomic oxygen species, surface diffusion of oxygen species to active sites for reduction (charge transfer), partial reduction of oxygen species, and combination of oxygen species with oxygen vacancy on the surface. While it is difficult to follow all these elementary steps, it is well accepted that these processes may proceed faster on nanostructured surfaces (such as our SDC-decorated hollow fiber cathode), which provide more active sites for adsorption, dissociation, and reduction of oxygen species[13]. Also, it may provide more oxygen vacancies on the surface that help the combination of reduced oxygen species with oxygen vacancy[42]. While the detailed mechanisms are yet to be unraveled, our results showed that the hollow fiber-based composite electrodes have lower ASR and higher characteristic frequencies, implying that the unique electrode architecture has potential to dramatically enhance fuel cell performance.

\section{Conclusions}

In summary, we have successfully prepared hollow nanofiber of PBSC by electrospinning and successfully bonded the fiber network on a GDC electrolyte membrane using PVB and a SDC 
bonding layer, creating a cathode consisting of unique three dimensional hollow fiber networks with high porosity and straight path for efficient charge and mass transfer. When tested in a $\mathrm{Ni}$ GDC anode supported cell with a thin GDC electrolyte membrane, peak power densities of 0.36 , 0.62 , and $1.11 \mathrm{Wcm}^{-2}$ are demonstrated at $450{ }^{\circ} \mathrm{C}, 500{ }^{\circ} \mathrm{C}$ and $550{ }^{\circ} \mathrm{C}$, respectively, much higher than those of the cell with a cathode derived from slurry of nano-sized powders of similar composition under the same testing conditions (humidified hydrogen as fuel and ambient air as

oxidant). In addition, the single cells show stable and high power output $\left(0.95 \mathrm{Wcm}^{-2}\right)$ when operated at a constant cell voltage of $0.6 \mathrm{~V}$ at $550{ }^{\circ} \mathrm{C}$ for more than 260 hours. This unique electrode architecture is attractive not only for a new generation of intermediate-temperature fuel cells with high performance and excellent stability, but also for other types of energy conversion and storage systems, including batteries, super capacitors, dye-sensitized solar cells, and photocatalysis.

\section{Acknowledgements}

This material is based upon work supported as part of the ARPAR-E REBELS Program, the U.S. Department of Energy under award number DE-AR0000502, the U.S. National Science Foundation (DMR-1210792), and Guangdong Innovative and Entrepreneurial Research Team Program (No. 2014ZT05N200).

\section{Author contribution}

M. Liu, Y. Chen, and D. Ding conceived the project. Y. Chen, R. Hu, T. Wei, and B. Rainwater fabricated the symmetrical cells and single cells, drafted the manuscript, and conducted data analysis of the electrochemical measurements and microstructure characterization (SEM). Y. 
Ding performed TEM characterization and analysis. Y. Zhang performed the modeling and simulation of porous electrodes. Y. Bu, B. Zhao, and D. Ding contributed to fiber fabrication and X-ray analysis. Y. Chen, F. Chen, C. Yang, and J. Liu contributed to discussion of the electrochemical data. All authors contributed to writing the paper.

\section{Competing financial interests}

The authors declare no competing financial interests.

\section{References}

[1] L. Carrette, K.A. Friedrich, U. Stimming, Fuel Cells, 1 (2001) 5-39.

[2] S. Tao, J.T.S. Irvine, Nat Mater, 2 (2003) 320-323.

[3] Z. Shao, S.M. Haile, Nature, 431 (2004) 170-173.

[4] Z. Zhan, D.M. Bierschenk, J.S. Cronin, S.A. Barnett, Energy Environ. Sci., 4 (2011) 3951-3954.

[5] E.D. Wachsman, K.T. Lee, Science, 334 (2011) 935-939.

[6] M. Liu, M.E. Lynch, K. Blinn, F.M. Alamgir, Y. Choi, Mater. Today, 14 (2011) 534-546.

[7] N.Q. Minh, M.B. Mogensen, Electrochem. Soc. Interface, 22 (2013) 55-62.

[8] Y. Zhou, H. Wu, T. Luo, J. Wang, Y. Shi, C. Xia, S. Wang, Z. Zhan, Adv. Energy Mater., 5 (2015) 1500375.

[9] T.Z. Sholklapper, H. Kurokawa, C.P. Jacobson, S.J. Visco, L.C. De Jonghe, Nano Lett., 7 (2007) 2136-2141.

[10] D. Ding, X. Li, S.Y. Lai, K. Gerdes, M. Liu, Energy Environ. Sci., 7 (2014) 552-575.

[11] Y. Guo, J. Hu, L. Wan, Adv. Mater., 20 (2008) 2878-2887.

[12] X. Lai, J.E. Halpert, D. Wang, Energy Environ. Sci., 5 (2012) 5604-5618.

[13] S.P. Jiang, Int. J. Hydrog. Energy, 37 (2012) 449-470.

[14] D. Ding, M. Liu, Z. Liu, X. Li, K. Blinn, X. Zhu, M. Liu, Adv. Energy Mater., 3 (2013) 1149-1154.

[15] M. Zhi, S. Lee, N. Miller, N.H. Menzler, N. Wu, Energy Environ. Sci., 5 (2012) 7066-7071.

[16] M. Zhi, N. Mariani, R. Gemmen, K. Gerdes, N. Wu, Energy Environ. Sci., 4 (2011) 417-420.

[17] J.G. Lee, J.H. Park, Y.G. Shul, Nat. Commun., 5 (2014).

[18] P.S. Kumar, J. Sundaramurthy, S. Sundarrajan, V.J. Babu, G. Singh, S.I. Allakhverdiev, S. Ramakrishna, Energy Environ. Sci., 7 (2014) 3192-3222.

[19] J.G. Lee, C.M. Lee, M.G. Park, S.-J. Jung, Y.G. Shul, Electrochim. Acta, 108 (2013) 356-360.

[20] Y. Jeon, D.-H. Park, J.-I. Park, S.-H. Yoon, I. Mochida, J.-H. Choy, Y.-G. Shul, Sci. Rep., 3 (2013).

[21] H.W. Park, D.U. Lee, P. Zamani, M.H. Seo, L.F. Nazar, Z. Chen, Nano Energy, 10 (2014) 192-200.

[22] D. Ding, B. Liu, Z. Zhu, S. Zhou, C. Xia, Solid State Ionics, 179 (2008) 896-899.

[23] Y. Chen, Y. Zhang, J. Baker, P. Majumdar, Z. Yang, M. Han, F. Chen, ACS Appl. Mater. Interfaces, 6 (2014) 5130-5136.

[24] Y. Chen, J. Bunch, T. Li, Z. Mao, F. Chen, J. Power Sources, 213 (2012) 93-99.

[25] S.-M. Park, J.-S. Yoo, Anal. Chem., 75 (2003) 455 A-461 A.

[26] F.S. Baumann, J. Fleig, M. Konuma, U. Starke, H.-U. Habermeier, J. Maier, J. Electrochem. Soc., 152 (2005) A2074-A2079. 
[27] G. Pike, C. Seager, Phy. Rev. B, 10 (1974) 1421.

[28] L. Hu, D.S. Hecht, G. Grüner, Nano Lett., 4 (2004) 2513-2517.

[29] D. Stauffer, A. Aharony, Introduction to percolation theory, CRC press, 1994.

[30] H. Wu, L. Hu, M.W. Rowell, D. Kong, J.J. Cha, J.R. McDonough, J. Zhu, Y. Yang, M.D. McGehee, Y. Cui, Nano Lett., 10 (2010) 4242-4248.

[31] J.H. Kim, M. Cassidy, J.T.S. Irvine, J. Bae, J. Electrochem. Soc., 156 (2009) B682-B689.

[32] H. Ding, X. Xue, Electrochim. Acta, 55 (2010) 3812-3816.

[33] E. Perry Murray, M.J. Sever, S.A. Barnett, Solid State Ionics, 148 (2002) 27-34.

[34] H. Lv, B.-Y. Zhao, Y.-J. Wu, G. Sun, G. Chen, K.-A. Hu, Mater. Res. Bull., 42 (2007) 1999-2012.

[35] S. Choi, S. Yoo, J. Kim, S. Park, A. Jun, S. Sengodan, J. Kim, J. Shin, H.Y. Jeong, Y. Choi, G. Kim, M. Liu, Sci. Rep., 3 (2013).

[36] N.Q. Minh, J. Am. Ceram. Soc., 76 (1993) 563-588.

[37] M.H.D. Othman, N. Droushiotis, Z. Wu, G. Kelsall, K. Li, Adv. Mater., 23 (2011) 2480-2483.

[38] M. Liu, H. Hu, J. Electrochem. Soc., 143 (1996) L109-L112.

[39] L. Li, X. Yin, S. Liu, Y. Wang, L. Chen, T. Wang, Electrochem. Commun., 12 (2010) 1383-1386.

[40] S. Chaudhari, M. Srinivasan, J. Mater. Chem., 22 (2012) 23049-23056.

[41] J. Xu, D. Xu, Z. Wang, H. Wang, L. Zhang, X. Zhang, Angew. Chem. Int. Ed., 52 (2013) 3887-3890.

[42] Z. Jiang, C. Xia, F. Chen, Electrochim. Acta, 55 (2010) 3595-3605. 


\section{Graphical Abstract}

An intermediate-temperature fuel cell (ITFC) based on a hollow nanofiber cathode of $\mathrm{PrBa}_{0.5} \mathrm{Sr}_{0.5} \mathrm{Co}_{2} \mathrm{O}_{5+\delta}$ (PBSC) and a freeze-drying tape-casted anode demonstrates excellent peak power density $\left(\sim 1.11 \mathrm{~W} \mathrm{~cm}^{-2}\right.$ at $\left.550^{\circ} \mathrm{C}\right)$ and reasonable stability, ideally suited for distributed generation.
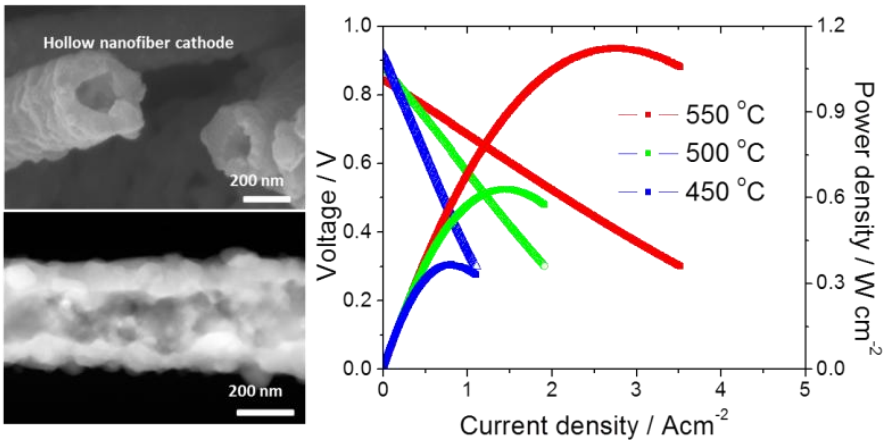